\title{
Evaluation of Children Receiving Tissue Plasminogen Activator Therapy for Thrombosis: Single Center Experience
}

\author{
(1) Ahmet Yöntem¹, (1) Göksel Leblebisatan², (1) Dinçer Yıldızdaş¹, (1) Hatice Illgen Şaşmaz², (1) Sevcan \\ Erdem³, (1) Fadli Demir33 , Engin Melek ${ }^{4}$, (1) Aysun Karabay Bayazıt 4
}

${ }^{1}$ Çukurova University Faculty of Medicine, Department of Pediatric Intensive Care Unit, Adana, Turkey

${ }^{2}$ Çukurova University Faculty of Medicine, Department of Pediatric Hematology, Adana, Turkey

${ }^{3}$ Çukurova University Faculty of Medicine, Department of Pediatric Cardiology, Adana, Turkey

${ }^{4}$ Çukurova University Faculty of Medicine, Department of Pediatric Nephrology, Adana, Turkey

\begin{abstract}
Aim: In this retrospective study, our objective was to evaluate children with arterial or venous thromboembolism, who were treated with tissue plasminogen activator (tPA) in our hospital.

Materials and Methods: The medical records of 56 tPA treatments administered to 53 patients with thrombosis in the paediatric intensive care unit and paediatric clinic at Çukurova University, Balcalı Hospital between September 2013 and August 2018, were investigated retrospectively. Results: Thirty-three of the patients were males (58.9\%). The median age was 13.5 months (0-203 months). Fifty-two of the patients received low-dose tPA treatment (91.2\%) and the mean treatment duration was 63.8 \pm 43.3 hours (3-192 hours). Thrombolytic treatment was administered to 38 patients $(67.8 \%)$ with catheter-related arterial thrombus, to 8 patients (14.3\%) with intracardiac thrombus, to 4 patients (7.2\%) with pulmonary arterial thrombus, and to 6 patients (10.7\%) with deep venous thrombus. No complication was observed in 47 treatments (83.9\%). However, 7 patients had minor (12.5\%) and 2 patients had major bleeding (3.6\%). Recanalization could not be achieved in 8 cases (14.3\%) and 4 patients underwent thrombectomy. The use of anticoagulant treatment with tPA did not change the complication rate or the success rate of the recanalization.
\end{abstract}

Conclusion: We determined that low-dose tPA treatment was effective in the treatment of life-, limb- or organ-threatening arterial and venous thromboembolism in children. However, randomized studies with larger sample sizes and control groups are required.

Keywords: Alteplase, tissue plasminogen activator, thrombosis, venous, arterial

\section{Introduction}

Thrombosis is rare in childhood; however, the rate of diagnosis arterial thromboembolism (ATE) and venous thromboembolism (VTE) has increased as a result of the early diagnosis by using the latest imaging techniques (1). It is known that the risk of thromboembolism increases in cases of cardiac, oncological/haematological diseases, central or arterial catheterization, or underlying predisposition to thrombosis $(2,3)$. There are studies showing that the incidence of venous thrombosis among children was between 
18.8 and 58 per 10,000 hospital admissions $(4,5)$. Arterial thromboembolism is less common than VTE in childhood. In a retrospective cohort study, the reported incidence of arterial thrombosis in the extremity was 2.35/10,000 (6). The incidence of peripheral arterial thrombosis was between $1.2 \%$ and $3.2 \%$ in critically-ill children $(3,7)$. It was reported that the risk of arterial thrombosis increases in children depending on their young age and low body weight and the incidence of arterial thrombosis might increase by up to $11.4 \%$ after cardiac catheterization (8).

Streptokinase, urokinase, and tissue plasminogen activator (tPA) are the main agents used in thrombolytic therapy. TPA is the most preferred medical treatment in children. The relatively shorter half-life (approximately 5 minutes) and the lower anaphylactic reaction risk in repeated use are the advantages of tPA. The success rate of thrombolytic treatment differs in arterial and venous thrombosis (9). Guidelines based on experience in the treatment of the adults are used during the therapeutic approach to childhood thrombosis. Although the use of tPA has increased in paediatric patients as a thrombolytic agent, there are conflicting data in the literature about the optimal dosing and treatment duration.

In this study, the aim was to evaluate the efficacy and safety of tPA treatment in paediatric patients, who were under tPA treatment or under follow-up for ATE or VTE with various diagnoses.

\section{Materials and Methods}

\section{Patient Population}

Following the approval of the Ethics Committee, the medical records of 56 treatments administered to 53 patients, who were treated with tPA due to thrombosis in the paediatric intensive care and paediatric clinic between September 2013 and August 2018 in the Çukurova University Hospital, were investigated retrospectively. Regarding the diagnosis and follow-up, echocardiography was used for intracardiac thrombus and Doppler ultrasonography for intravascular thrombus. Computed tomography was used in cases of suspected pulmonary embolism. The location of the thrombus was classified as: (1) Catheter-related arterial thrombus including secondary to cardiac catheterization and arterial pressure monitoring; (2) pulmonary artery; (3) intracardiac thrombosis including atrial and ventricular; and (4) deep venous thrombosis (DVT) of the femoral vein or portal vein.

\section{Treatment}

The tPA doses and concomitant anticoagulant treatment options were administered according to the recommendations of the clinicians. Plasminogen levels could not be measured in this hospital. During the tPA transfusion, the prothrombin time/international normalized ratio, activated partial thromboplastin time and fibrinogen level were assessed before tPA treatment, 4 hours after the start of the infusion, and with 6-8-hour intervals after infusion. If the fibrinogen level decreased below $100 \mathrm{mg} / \mathrm{dL}, 10 \mathrm{~mL} / \mathrm{kg}$ fresh frozen plasma (FFP) was administered to preserve a plasminogen level of $100 \mathrm{mg} / \mathrm{dL}$. Platelet count was measured twice a day in order to maintain a platelet level above $100 \times 10^{9} / \mathrm{L}$. In cases of major or minor bleeding, tPA treatment was discontinued and FFP was administered. Antifibrinolytic treatment was used in cases of major bleeding. Daily Doppler ultrasonography or echocardiographic examination was performed in the $6^{\text {th }}$ hour of the treatment and during the follow-up in patients receiving tPA treatment. In those patients who received tPA treatment due to thrombus in the extremity after cardiac catheterization, the treatment was terminated if the circulation and pulse examination were normal or recanalization was observed during Doppler ultrasonography. The treatment was also terminated if recanalization was determined with Doppler ultrasonography or echocardiography in patients without cardiac catheterization.

The patients were evaluated for age, sex, primary diagnosis, comorbidities, thrombolytic treatment indication, thrombotic vessels, anticoagulant treatment concomitant to tPA treatment, tPA dose and duration, complications related to thrombolysis, duration of hospitalization, thrombectomy, and amputation. Vital organ haemorrhage and any event requiring discontinuation of thrombolytic therapy are described as major and mucosal bleeding or bleeding from any skin insertion site described as minor complications. The patients were divided into two subgroups according to the tPA dosage, namely low-dose $(<0.1 \mathrm{mg} / \mathrm{kg} /$ hour) or high-dose ( $\geq 0.1 \mathrm{mg} / \mathrm{kg} /$ hour) (10).

\section{Statistical Analysis}

SPSS v20.0 software package was used for the statistical analysis. Categorical measurements are given as numbers and percentages, and numeric measurements as mean and standard deviation values (if necessary, median and minimum/maximum values were also referred). 
Table I. Characteristics of the patients

\begin{tabular}{|l|l|}
\hline & $\mathbf{n}(\%)$ \\
\hline Sex & \\
Male & $33(58.9)$ \\
Female & $23(41.1)$ \\
\hline Primer diagnosis & \\
Cardiological & $34(60.7)$ \\
Nephrological & $11(19.6)$ \\
Hemato-oncological & $4(7.2)$ \\
Others & $7(12.5)$ \\
\hline Comorbidity & \\
Infection & $11(19.6)$ \\
Respiratory & $6(10.7)$ \\
Cardiac & $5(8.9)$ \\
Hepatic & $2(3.6)$ \\
\hline Indication of tPA & \\
Arterial thrombosis (catheter related) & $38(67.8)$ \\
Intracardiac thrombosis & $8(14.3)$ \\
Central venous thrombosis & $6(10.7)$ \\
Pulmonary thrombosis & $4(7.2)$ \\
\hline Therapy & \\
tPA & $14(25.0)$ \\
tPA+Low-molecular-weight heparin & $27(48.2)$ \\
tPA+Unfractionated heparin & $15(26.8)$ \\
\hline Complication & \\
None & $47(83.9)$ \\
Minor & $7(12.5)$ \\
Major & $2(3.6)$ \\
\hline Recanalization & \\
Not achieved & $8(14.3)$ \\
Partial & $18(32.1)$ \\
Complete & $30(53.6)$ \\
\hline Surgery/thrombectomy & $4(7.1)$ \\
\hline Amputation & $2(3.6)$ \\
\hline tPA: Tissue plasminogen activator & \\
\hline & \\
\hline
\end{tabular}

\section{Results}

Fifty-six tPA treatments from a total of 53 cases were included in this study. Thirty-three of the participants were male (58.9\%). The median age was 13.5 months (0-203 months). Thirty-four of the patients (60.7\%) had cardiological, 11 (19.6\%) nephrological and 4 (7.1\%) haemato-oncological diseases (Table I). The most common comorbidity was infection (19.6\%).

Thrombolytic treatment was administered to 38 patients $(67.8 \%)$ with catheter-related arterial thrombus, to 8 patients $(14.3 \%)$ with intracardiac thrombus, to 4 patients (7.2\%) with pulmonary arterial thrombus, and 6 patients (10.7\%) with DVT. Catheter-related arterial thrombus was associated with younger age $(p=0.001)$. No significant difference was found between the groups in terms of tPA dosage and tPA infusion time $(p=0.46$ and $p=0.44$, respectively).
The mean value of the tPA dose in all treatments was $0.07 \pm 0.09 \mathrm{mg} / \mathrm{kg} / \mathrm{hour}$ (range: $0.02-0.5 \mathrm{mg} / \mathrm{kg} / \mathrm{hour}$ ) and the duration of the tPA treatment was $63.8 \pm 43.3$ hours (3-192 hours). Minor and major bleeding emerged in 7 (12.5\%) and 2 cases $(3.6 \%)$, respectively, and no complication was observed in 47 treatments (83.9\%). The tPA dose and treatment duration in patients with or without bleeding are listed in Table II.

Complete, partial and no recanalization was achieved in $30(53.6 \%), 18(32.1 \%)$ and $8(14.3 \%)$ treatments, respectively. The patients were evaluated in two groups as complete recanalization and partial/no canalization. There was no significant relationship between age, primary diagnosis, tPA dosage, and the duration of the tPA treatment. Four patients underwent thrombectomy due to thrombosis in the femoral artery $(n=1)$, in the external iliac vein $(n=1)$, in the portal vein $(n=1)$, and the pulmonary artery $(n=1)$. Two of 38 patients $(5.2 \%)$ who had thrombus following the arterial catheterization in the extremity did not respond to the medical treatments and underwent amputation. Two patients with DVT, who were unresponsive to tPA treatment, were discharged with low molecular weight heparins (LMWH) treatment. Fourteen of the treatments consisted of only tPA (25.0\%), 27 (48.2\%) had concomitant LMWH and 15 (26.8\%) had concomitant unfractionated heparin. The median value of the LMWH and unfractionated heparin doses were $2 \mathrm{mg} / \mathrm{kg} /$ day and 20 units $/ \mathrm{kg} / \mathrm{h}$, respectively. The use of anticoagulant treatment with tPA did not alter the complication rate or the success rate of recanalization $(p>0.05)$.

tPA dose was evaluated in two groups, namely, lowdose $(<0.1 \mathrm{mg} / \mathrm{kg} /$ hour $)$ or high-dose ( $\geq 0.1 \mathrm{mg} / \mathrm{kg} /$ hour ). The duration of the tPA treatment was $69.3 \pm 41.5$ hours (3-192 hours) and 8.6 \pm 3.6 hours (6-13 hours) in the low-dose and high-dose groups, respectively. Complications were observed in two patients in the high-dose group (40\%) and seven patients in the low-dose group (13.7\%). The characteristics of the patients with low-dose and high-dose tPA treatment are listed in Table III. Statistical analysis could not be done due to the low sample size in the high-dose group.

\section{Discussion}

The aim of the treatment in thromboembolism is the prevention of growth of the clot and embolism, the restoration of circulation, the limitation of long-term sequel, and a decrease in recurrence risk. Anticoagulant agents, such as unfractionated heparin, low-molecularweight heparin, vitamin $\mathrm{K}$ antagonists, or thrombolytic 
Table II. Characteristics of the patients with and without bleeding complications

\begin{tabular}{|l|l|l|l|l|}
\hline & $\begin{array}{l}\text { All patients } \\
\text { (n=56) }\end{array}$ & $\begin{array}{l}\text { Patients without } \\
\text { bleeding complication } \\
\text { (n=47) }\end{array}$ & $\begin{array}{l}\text { Patients with bleeding } \\
\text { complication } \\
\text { (n=9) }\end{array}$ & p-value \\
\hline $\begin{array}{l}\text { Age } \\
\text { (months) }\end{array}$ & $\begin{array}{l}\mathbf{n}=2 \pm 68.7 \\
13.5(0-203)\end{array}$ & $\begin{array}{l}62.3 \pm 70.5 \\
18.0(1-203)\end{array}$ & $\begin{array}{l}30.8 \pm 54.7 \\
6.0(0-166)\end{array}$ & 0.07 \\
\hline tPA dosage (mg/kg/h) & $0.07 \pm 0.09$ & $0.05 \pm 0.04$ & $0.14 \pm 0.19$ & $0.06(0.03-0.50)$ \\
\hline $\begin{array}{l}\text { tPA infusion time } \\
\text { (hours) }\end{array}$ & $0.05(0.02-0.5)$ & $0.05(0.02-0.25)$ & 0.06 & 0.01 \\
\hline
\end{tabular}

Table III. Characteristics of the patients with low-dose and high-dose tissue plasminogen activator treatment

\begin{tabular}{|c|c|c|}
\hline & $\begin{array}{l}\text { Low-dose tPA } \\
(n=51) \\
\text { mean } \pm S D \\
\text { median (min-max) }\end{array}$ & $\begin{array}{l}\text { High-dose tPA } \\
(n=5) \\
\text { mean } \pm S D \\
\text { median (min-max) }\end{array}$ \\
\hline $\begin{array}{l}\text { Age } \\
\text { (months) }\end{array}$ & $\begin{array}{l}59.8 \pm 70.2 \\
17.0(0-203)\end{array}$ & $\begin{array}{l}31.2 \pm 49.8 \\
12.0(5-120)\end{array}$ \\
\hline $\begin{array}{l}\text { tPA dosage (mg/ } \\
\mathrm{kg} / \mathrm{h})\end{array}$ & $\begin{array}{l}0.05 \pm 0.01 \\
0.05(0.02-0.06)\end{array}$ & $\begin{array}{l}0.30 \pm 0.18 \\
0.25(0.12-0.50)\end{array}$ \\
\hline $\begin{array}{l}\text { tPA infusion } \\
\text { time (hours) }\end{array}$ & $\begin{array}{l}69.3 \pm 41.5 \\
72.0(3-192)\end{array}$ & $\begin{array}{l}8.6 \pm 3.6 \\
6.0(6-13)\end{array}$ \\
\hline $\begin{array}{l}\text { Complication, } \\
\text { n (\%) } \\
\text { None } \\
\text { Minor } \\
\text { Major }\end{array}$ & $\begin{array}{l}33(86.3) \\
6(11.8) \\
1(2.0)\end{array}$ & $\begin{array}{l}3(60.0) \\
1(20.0) \\
1(20.0)\end{array}$ \\
\hline $\begin{array}{l}\text { Recanalization, } \\
\text { n (\%) } \\
\text { Not achieved } \\
\text { Partial } \\
\text { Complete }\end{array}$ & $\begin{array}{l}5(9.8) \\
17(33.3) \\
29(56.9)\end{array}$ & $\begin{array}{l}3(60.0) \\
1(20.0) \\
1(20.0)\end{array}$ \\
\hline
\end{tabular}

agents (streptokinase, urokinase, and tPA) may be used in the treatment of children with thromboembolism (11-13). While the anticoagulant treatment prevents the growth of thrombus, decreases the risk of embolism, it also enables the shrinkage of the thrombus by its inherent fibrinolytic mechanism. Although the use of tPA has increased in paediatric patients as a thrombolytic agent, general contraindications to thrombolysis include active bleeding, concurrent bleeding diathesis, recent major surgery or trauma, intracranial haemorrhage, and extreme prematurity $(14,15)$.

Although the guidelines do not recommend thrombolysis in paediatric patients with DVT in most cases of the clinical thrombosis, it should be considered in cases of pulmonary embolism with hemodynamic compromise or venous thrombus that may lead to irreversible organ or extremity damage $(16,17)$. The goal of thrombolysis is the dissolution of the vascular occlusion caused by thrombus with the help of the activation of the fibrinolytic system. The primary indication for thrombolysis is limb- or lifethreatening acute or subacute occlusive venous or arterial thrombosis. Strong indications for thrombolysis include pulmonary embolism with hypotension or shock, superior vena cava syndrome, bilateral renal vein thrombosis, congenital heart disease with shunt thrombosis, large ( $>2$ $\mathrm{cm}$ ) atrial thrombus, and cerebral sinovenous thrombosis with neurologic impairment (16). In this study, 6 patients with DVT $(10.7 \%)$ received tPA treatment. Severe acute abdominal pain developed in two of these patients and magnetic resonance examination revealed portal vein thrombosis. Due to the development of hemodynamic imbalance, acute hepatic failure, and acute kidney failure, tPA treatment was initiated to prevent progress towards chronic liver failure. Doppler ultrasonography showed that flow was restored in the portal vein of the patient, whose clinical condition improved. The remaining four patients had diffuse thrombosis starting from the popliteal vein, extending to the superior iliac vein, and had the risk of extremity loss. In one of these four patients who received tPA due to a risk of extremity loss, a resolution could not be achieved and surgical thrombectomy was necessary. These patients had risk factors, such as immobilization, nephrotic syndrome, and previous abdominal surgery, which may cause thrombophilia.

A literature review evaluated 413 children who received thrombolytic treatment with streptokinase, urokinase, or tPA. It was reported that a complete recanalization was achieved in 53\%, 43\%, and 69\% patients, respectively (18). There are also studies where low-dose heparin infusion or low-molecular-weight heparin were added to the thrombolytic treatment $(10,19)$. Concomitant use of anticoagulation with systemic thrombolysis is recommended to prevent new thrombus formation during thrombolysis, as clot lysis releases active thrombin which bonds to thrombi (10). In this study, 14 patients (25.0\%) received only $\mathrm{tPA}$, and $\mathrm{LMWH}$ and unfractionated heparin 
was added to the tPA treatment in 27 (48.2\%) and 15 (26.8\%) patients, respectively. The use of anticoagulant agents did not alter the complication rate or the success rate of the recanalization. Although it may be concluded that anticoagulant treatment concomitant to tPA did not cause any significant difference regarding the resolution, a definitive conclusion was not possible because of the small sample size of this study.

The rate of bleeding complications and the success rate of the thrombolytic treatment in children differs between health centres. The rate of complete and partial recanalization with thrombolytic treatment was observed to be between $26-88 \%(18-22)$. In this study, the rate of complete and partial recanalization was $85.7 \%$. In eight patients, recanalization could not be achieved and four patients underwent thrombectomy. Two patients did not respond to medical treatment and underwent amputation. Albisetti (18) reported that the rates of minor and major bleeding complications were $26 \%$ and $17 \%$, respectively, in patients treated with tPA. Newall et al. (9) evaluated 26 paediatric patients with arterial or venous thrombosis, who were treated with tPA and reported a major haemorrhage rate of $11.5 \%$. In this study, both the major and minor bleeding complication rate was slightly lower than the literature.

Close follow-up protocols relating to the anticoagulant treatment concomitant to the high- and low-dose systemic thrombolytic therapy and haemorrhage have been previously reported (20). The reported range of dosage of tPA for children is between 0.01 and $0.6 \mathrm{mg} / \mathrm{kg} / \mathrm{h}$. Tarango AND Manco-Johnson (10) suggested that the duration of tPA treatment is 6-72 hours for low-dose and 2-6 hours for highdose tPA. The longer duration of tPA treatment compared to the literature did not lead to a higher complication rate in this study. There are studies showing that lowdose tPA treatment was as effective as high-dose tPA treatment (18-21). In their retrospective study, Gupta et al. (22) evaluated the data of 80 paediatric patients treated with high-dose tPA over 14 years and reported that major complications emerged in $40 \%$ of patients and that highdose tPA treatment had a poor safety profile. Moreover, all patients in this study received unfractionated heparin infusion before tPA treatment. In this study, 52 patients received low-dose, and 5 patients received high-dose tPA treatment. The authors observed complications in two of the high-dose patients (40\%) and seven of the low-dose patients (13.5\%). Although the patient groups and success rates were comparable, the complication rate was lower in our study. With regard to our findings, the necessity of the high-dose tPA and concomitant treatments may be questioned.

\section{Study Limitations}

There were limitations to this study. TPA and concomitant anticoagulant treatment options were used based on the recommendations of the clinicians. A balanced distribution between the groups could not be achieved due to the retrospective study design. It would be better if the data on the duration of thrombosis before tPA treatment was available as it may have affected the success rate of tPA. Statistical analysis could not be performed because of the small number of patients receiving high-dose tPA treatment.

\section{Conclusion}

In this study, we detected that low-dose tPA treatment was effective in the treatment of life-, limb- or organthreatening arterial and venous thromboembolism in children. Howe ver, randomized studies with larger sample sizes and control groups are required.

\section{Ethics}

Ethics Committee Approval: The Ethics Committee of Çukurova University Faculty of Medicine approved the study (2019-86).

Informed Consent: Informed consent was not obtained because this was a retrospective study.

Peer-rev iewed: Internally and externally peer-reviewed.

\section{Authorship Contributions}

Surgical and Medical Practices: F.D., S.E., Concept: G.L., D.Y., A.K.B., Design: A.Y., F.D., E.M., Data Collection or Processing: A.Y., G.L., S.E., Analysis or Interpretation: D.Y., A.K.B., Literature Search: A.Y., H.I.Ş., E.M., Writing: A.Y., G.L., D.Y.,

Conflict of Interest: The authors declared no conflict of interest.

Financial Disclosure: The authors declared that this study received no financial support.

\section{References}

1. Chan AK, Monagle P. Updates in thrombosis in pediatrics: where are we after 20 years? Hematol Am Soc Hematol Educ Program 2012; 2012:439-44.

2. Polikoff LA, Faustino EV. Venous thromboembolism in critically ill children. Curr Opin Pediatr 2014; 26:286-91.

3. Brotschi B, Hug MI, Kretschmar O, et al. Incidence and predictors of cardiac catheterisation-related arterial thrombosis in children. Heart 2015; 101:948-95. 
4. Raffini L, Huang YS, Witmer C, et al. Dramatic increase in venous thromboembolism in children's hospitals in the United States from 2001 to 2007. Pediatrics 2009; 124:1001-8.

5. Setty BA, O'Brien SH, Kerlin BA. Pediatric venous thromboembolism in the United States: a tertiary care complication of chronic diseases. Pediatr Blood Cancer 2012; 59:258-64.

6. Totapally BR, Raszynski A, Khan D, et al. Extremity arterial thromboses in hospitalized children: a national database analysis of prevalence and therapeutic interventions. Pediatr Crit Care Med 2019; 20:154-9.

7. Albisetti M, Schmugge M, Haas R, et al. Arterial thromboembolic complications in critically ill children. / Crit Care 2005; 20:296300.

8. Brotschi B, Hug MI, Latal B, et al. Incidence and predictors of indwelling arterial catheter-related thrombosis in children. J Thromb Haemost 2011; 9:1157-62.

9. Newall F, Browne M, Savoia H, et al. Assessing the outcome of systemic tissue plasminogen activator for the management of venous and arterial thrombosis in paediatrics. I Pediatr Hematol Oncol 2007; 29:269-73.

10. Tarango C, Manco-Johnson M). Pediatric thrombolysis: a practical Approach. Front Pediatr 2017;5:260.

11. Lyle CA, Sidonio RF, Goldenberg NA. New developments in pediatric venous thromboembolism and anticoagulation, including the target-specific oral anticoagulants. Curr Opin Pediatr 2015; 27:18-25.

12. Ko RH, Michieli C, Lira IL, et al. FondaKIDS II: long-term follow up data of children receiving fondaparinux for treatment of venous thromboembolic events. Thromb Res 2014; 134:643-7.

13. Law C, Raffini L. A guide to the use of anticoagulant drugs in children. Pediatr Drugs 2015; 17:105-14.
14. Kukreja K, Gruppo R, Chima R, Ristagno R, Racadio J. Developing a pediatric endovascular thrombolysis program: a single-center experience. Pediatr Radiol 2013; 43:1024-9.

15. Manco-Johnson MJ, Grabowski EF, Hellgreen $M$, et al. Recommendations for tPA thrombolysis in children. On behalf of the Scientific Subcommittee on Perinatal and Pediatric Thrombosis of the Scientific and Standardization Committee of the International Society of Thrombosis and Haemostasis. Thromb Haemost 2002; 88:157-8.

16. Monagle $\mathrm{P}$, Chan AKC, Goldenberg NA, et al. Antithrombotic Therapy in Neonates and Children. Antithrombotic Therapy and Prevention of Thrombosis, 9th ed: American College of Chest Physicians Evidence-Based Clinical Practice Guidelines. Chest 2012; 141(Suppl 2):e737S-801S.

17. Monagle $\mathrm{P}$, Cuello CA, Augustine C, et al. American Society of Hematology 2018 Guidelines for management of venous thromboembolism: treatment of pediatric venous thromboembolism. Blood Adv 2018; 2:3292-316.

18. Albisetti M. Thrombolytic therapy in children. Thromb Res 2006; 118:95-105.

19. Wang M, Hays $T$, Balasa $V$, et al. Pediatric Coagulation Consortium. Low-dose tissue plasminogen activator thrombolysis in children. I Pediatr Hematol Oncol 2003; 25:37986.

20. Manco-Johnson MJ, Nuss R, Hays T, et al. Combined thrombolytic and anticoagulant therapy for venous thrombosis in children. I Pediatr 2000; 136:446-53.

21. Leary SE, Harrod VL, de Alarcon PA, et al. Low-dose systemic thrombolytic therapy for deep vein thrombosis in pediatric patients. J Pediatr Hematol Oncol 2010; 32:97-102.

22. Gupta AA, Leaker $M$, Andrew $M$, et al. Safety and outcomes of thrombolysis with tissue plasminogen activator for treatment of intravascular thrombosis in children. I Pediatr 2001; 139:682-8. 